(14) H. Levin et al.: Anal. Chem., 22, 188 (1950)

(15) F.H. Garner et al : J. Inst. Petroleum, 35, 161 (1949)

(16)'山口交之助, 井户文彦 (Yamaguchi, Ido): 東京大学航研军報 (J. Aeronaut. Research Inst., Tokyo Imp. Univ.) No.

\section{8,185 (1944)}

(17) L. Hock: Kolloidchem. Beichefte, 31 (6), 185 (1930)

(18) 岩本義虎 (Iwamoto)：日化 (J. Chcm. Soc. Japan), 52, 433 (1931)

\title{
水銀法食塩電解の理論分解電圧について
}

\section{Theoretical Decomposition Voltage of Sodium Chloride \\ Electrolysis with Mercury Cathode}

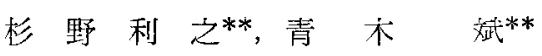

Toshiyuki Sugrno and Kiyoshi AOKI

\section{1. 緒言}

水鐉法食醏電解の理論分解電圧に関しては特定の条件 に乱いて二，二の計算がなされ(1)，3.1〜3.2 V が与え られているが, 最近極度に発達した電解槽の, 電压収支 ・電流分布或いは熱收支等の部門を研究し，電圧を更に 低下するためには，溶液の温度，食塩濃度，アマルガム のナトりウム濃度などに関して更に精密な值が要求され る. そこで熱力学の知識と公表されたデータ基いて或 程度の近似計算を行い，食塩水溶液の理論分解霍圧を溶 液の温度 $(T)$ 食塩の平均活量 $\left(a_{\text {上 }}\right)$ 及びアマルガム中 のナトリウムの濃度 $(C)$ の函数として表すことを融み 且つその結果を実用箐囲でノモグラフに作筡した。

\section{2. 水銀法食塩電解に関する理論分解電圧の 基本式}

電㥛に捻いてガス態の塩素と塩素イオンが平衡する電 位， $E_{+}$は次式で示される。

$$
E_{+}=E_{\mathrm{Cl}^{-}}{ }^{0}+(R T / 2 \boldsymbol{F}) \ln p_{\mathrm{Cl}_{2}}-(R T / F) \ln a_{\mathrm{Cl}^{-}}
$$

ここ, $E_{\mathrm{Cl}^{-}}{ }^{0}$ : 塩素の標準単極電位

$$
\begin{aligned}
& p_{\mathrm{Cl}_{2}} \text { : 気相の塩素分压 } \\
& a_{\mathrm{Cl}^{-}} \text {: 塩素イオンの活量 }
\end{aligned}
$$

である. 同様にアマルガム中のナトリウムがそのイオン と平衡する電位 $E_{-}$は次式炡よって示される.

$$
E_{-}=E_{\mathrm{Na}^{+}}{ }^{0}-(R T / F) \ln \left(a_{\mathrm{C}} / a_{\mathrm{Na}}\right)+(R T / F) \ln a_{\mathrm{Na}^{+}},
$$

ここル， $E_{\mathrm{Na}}+^{0}:$ ナリウムの標準単極電位

$$
\begin{aligned}
& a_{\mathrm{C}}: \text { アルルガム中のナトリウムの活量 } \\
& a_{\mathrm{Na}} \text { : 金属ナトリウムの活量 } \\
& a_{\mathrm{Na}}+\text { : ナトリウムイオンの活量 }
\end{aligned}
$$

である. 故に理論分解電圧 $E=E_{+}-E_{-}$次次式で示され 万.

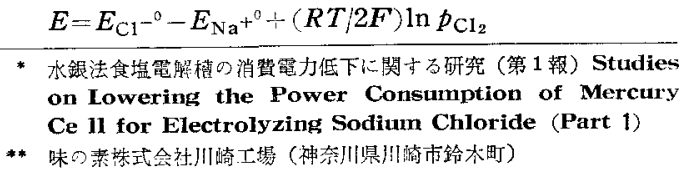

$$
\begin{aligned}
& +(R T / F) \ln \left(a_{\mathrm{C}} / a_{\mathrm{Na}}\right)-\left(R T / F \cdot \ln a_{\mathrm{Cl}^{-}}\right. \\
& -(R T / F) \ln a_{\mathrm{Na}^{+}}
\end{aligned}
$$

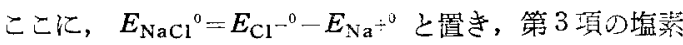
分压 $p_{\mathrm{Cl}_{2}}$ は通常の電解で多台ど $1 \mathrm{~atm}$ でするふらこれ 省省略乙，第 5 项，第 6 項に染いて， $a_{ \pm \mathrm{NaCl}}=\sqrt{a_{\mathrm{Na}^{+}} \cdot a_{\mathrm{Cl}}}$ を用いれば次の虾くになる。

$$
\begin{aligned}
E=E_{\mathrm{NaCl}}{ }^{0} & +(R T / \boldsymbol{F}) \ln \left(a_{\mathrm{C}} / a_{\mathrm{Na}}\right) \\
& -2(R T / \boldsymbol{F}) \ln a_{ \pm \mathrm{NaCl}}
\end{aligned}
$$

(1) 式注倫分解電圧の基本式でかり結局この三つの項 孝系の温度, 溶液中の食塩濃宽,アマルガム中うナトり ウム濃度の函数で表姑ばよいわけである。

\section{3. $\boldsymbol{E}_{\mathrm{NaCl}}{ }^{0}$ に関する近似式}

$E_{\mathrm{NaCl}}{ }^{0}$ は活量 1 なる食塩水溶液よりナトりウム及び

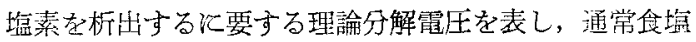

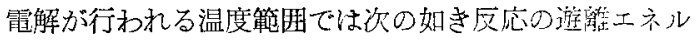
ギ一の変化より求めることが出来る.

$$
\begin{aligned}
& \mathrm{Na}(c)+1 / 2 \mathrm{Cl}_{2}(g)=\mathrm{NaCl}(c) \quad \Delta F_{1} \\
& \mathrm{NaCl}(c)=\mathrm{NaCl} \text { (in soln. } a=1) \frac{\Delta F_{2}}{\Delta F_{2}}
\end{aligned}
$$

即方 $E_{\mathrm{NaCl}}{ }^{\circ}=-\left(\Delta F_{1}+\overline{\Delta F_{2}}\right) / F$

\section{(a) $\Delta F_{1}$ の計算}

固態ナトリウムと気態鼠素より固態食壏を生成する反 応に括いて，任意温度の遊離エネルギーの変化沈次式か ら計算する。.

$$
d(\Delta F / T) / d T=-\Delta H / T^{2}
$$

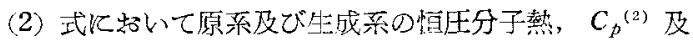
びその差, $\Delta C_{p}$ は次の如くである。

$C_{p}: \mathrm{Na}(c) 5.01+0.00536 \mathrm{~T} \quad 273 \sim 371^{\circ} \mathrm{K}$

$\mathrm{NaCl}(c) 10.79+0.00420 \mathrm{~T} \quad 273 \sim 1,074^{\circ} \mathrm{K}$

$\mathrm{Cl}_{2}$ (g) $8.28+0.00056 \mathrm{~T} \quad 273 \sim 2,000^{\circ} \mathrm{K}$ $\Delta C_{p}=1.64-0.00144 T$

即亏 $\Delta C_{p}$ 及び $\Delta H_{298}=-98321 \mathrm{cal} / \mathrm{mol}^{(3)}, \Delta F_{298}=$ $-91,792 \mathrm{cal} / \mathrm{mol}^{(4)}$ より $J F_{1}$ 求めた.

$$
\lrcorner F_{1}=-98,746+32.464 T-3.776 T \log T
$$$$
+0.00072 T^{2}
$$ 


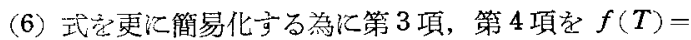
-3.776 $T \log T+0.00072 T^{2}$ と置き $273 \sim 373^{\circ} \mathrm{K}$ の間 で $f(T)$ 它求めたとこる士 $3 \mathrm{cal}$ の譟差範囲内で次の 如き一式で近似することが出宋た。

$$
f(T)=455-10.66 T
$$

即ち $273 \sim 371^{\circ} \mathrm{K}$ (ナトリウムの融点) の範国内で (6) 式は沃り如く簡易化された。

$$
\lrcorner F_{1}=-98,291+21.804 T
$$

(b) $1 \overline{\boldsymbol{F}}_{2}$ の計算

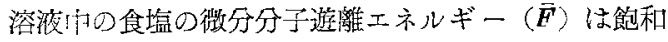
濃度に㔚いてはこれと平衡する固態食塩の有する遊離工

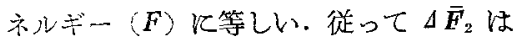

$$
\lrcorner \bar{F}_{2}=-2 R T \ln a_{ \pm \mathrm{KaCr}} \text {.satu. }
$$

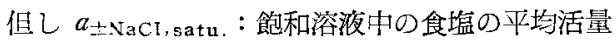

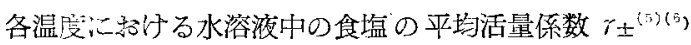
は既に与手えられている。この值から飽和溶液の平聕活量 係数を外搯して求め，0〜100 $\mathrm{C}$ の間で $\Delta \bar{F}_{2}$ を計算し て Table 1 の如き結果を得た.

Table 1 Values of $\bar{\Delta} F_{2}$

\begin{tabular}{l|c|c|c|c|c|c}
\hline Temp. (C) & 0 & 10 & 25 & 40 & 60 & 100 \\
\hline$\widetilde{F}_{2}(\mathrm{cal} / \mathrm{mol})$ & -1863 & -1968 & -2144 & -2273 & -2490 & -2826 \\
\hline
\end{tabular}

Table 1 ょり, $\Delta \bar{F}_{2}$ と絶対温度 $(T)$ との関係式を求

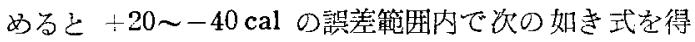
た。

$$
\lrcorner \bar{F}_{2}=809-9.85 T
$$

(4), (6), (8) より

$$
E_{\mathrm{NaCl}}{ }^{\prime \prime}=4.2820-(14.708+0.00031 T
$$$$
\left.-1.637 \log T-3.968 \log a_{ \pm \mathrm{NaCl} . \text { satu. }}\right)
$$

$$
\times 10^{-4} T(\mathrm{~V})
$$

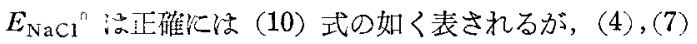
攻び（9）式を適用することにより+0.002 - - 0.001 V の愦差管围内で次の如く近似される。

$$
E_{\mathrm{racl}}{ }^{3}=4.2272-5.184 \cdot 10^{-4} T(\mathrm{~V})
$$

\section{4. $(\boldsymbol{R T} / \boldsymbol{F}) \ln \left(\boldsymbol{a}_{\mathrm{C}} / \boldsymbol{a}_{\mathrm{Na}}\right)$ に関する近似式}

固態ナトリウムがアマルガムに溶解するときの遊離エ ネルギーの変化， $\Delta \bar{F}_{3}$ 々次の如くでめる.

$$
J \bar{F}_{3}=R T \ln \left(a_{\mathrm{C}} / a_{\mathrm{Na}}\right)
$$

Lewis そび Kraus ${ }^{(7)}$ 金属ナトリウムと $0.206 \%$ ナ トリウムアマルガムとの間の起電力と温度係数を測定 し, Richard 及び Conant ${ }^{(8)} 0.551 \%$ 以下の滰度で, ナトリウムアマルガム間の起電力と温度係数桑測定し た.柴田没び織田 ${ }^{(9)(10)}$ は Lewis 及び Kraus 並びに Richard るび Conant の測定值を利用してアマルガム中 のナトリウムの活量を計算し，更にナトリウム及び水銀 の微分缷離エネルギーと微分熱含量，並びにアマルガム

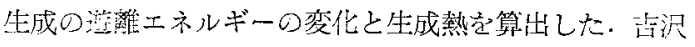

及び武藤 ${ }^{(11)}$ はポーラログラフ法を用いて $0.5 \%$ 以下の ナトリウムアマルガムが食塩水に対するときの平衡電位

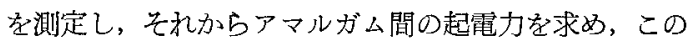
值と Richard 及び Conant の测定值加らそれぞれアマ ルガム中のナトリゥムの活量を算出した．これらのデー 夕を利用して $\overline{A F_{3}}$ を求めることが可能である。任意温 度の活量比は次式加求める。

$$
d \ln \left(a_{\mathrm{C}} / a_{\mathrm{Na}}\right) / d T=-\overline{\Delta H} / R T^{2}
$$

$\overline{\Delta H}$ は一般に温度の函数であるが適用温㠌 $\left(0 \sim 98^{\circ} \mathrm{C}\right)$ の 籁囲内で不変と見做した. 一方 Lewis 及び Kraus 这 びV Richard 及び Conant の測定值孝利朋し， 0.551

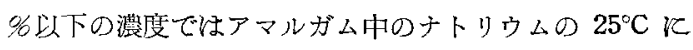
扣ける微分熱含量 $\overline{\Delta H}_{298}$ ほ次の如き実験式で表すこと が出来る。

$$
\overline{\Delta H_{298}}=-19,951-830 \mathrm{C}
$$

但し $C:$ アマルガム中のナトリウム百分率

（14）を（13）に代人して積分すると，

$$
\ln \left(a_{\mathrm{C}} / a_{\mathrm{Na}}\right)=(-19,951+830 C) / R T+k
$$

但 $L, k$ : 積分恒数

$T=298^{\circ} \mathrm{K}$ に括ける活量比の自然効数 $\ln \left(a_{\mathrm{C}} / a_{\mathrm{Na}}\right)_{298}$ 上し（15）式江代入して $k$ を消去すると，

$$
\begin{array}{r}
\ln \left(a_{\mathrm{C}} / a_{\mathrm{Na}}\right)=(19,951-830 C)(T-298) \\
/(298 R T)+\ln \left(a_{\mathrm{C}} / a_{\mathrm{Na}}\right)_{298}
\end{array}
$$

(12) 双び (16) より

$$
\begin{aligned}
\overline{d F}_{3}=(T & -298)(66.950-2.78 C) \\
& +R T \ln \left(a_{\mathrm{C}} / a_{\mathrm{Na}}\right)_{298}
\end{aligned}
$$

(a) (17) 式第 1 項の近似式

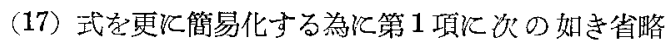
を行った. 即も $2.78 C(T-298)$ は $C=0 \sim 0.5 \%$ 程度, $T=273 \sim 371^{\circ} \mathrm{K}$ の間で使用するが, $C=0.5, T=371 て$ 約 $100 \mathrm{cal}$ の值を取る。そ故この項省省略すると最 大 $100 \mathrm{cal}$ の誤差妾生じ得るが，若し $C=0.25$ 与气

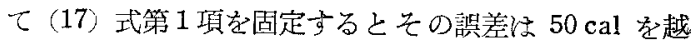
えず，次の如く表わされる。

$$
(T-298)(66.950-2.78 C) \div 66.255(T-298)
$$

(b) (17) 式第 2 項の近似式

吉洔及び武藤 ${ }^{(11)}$ が Richard 及び Conant の測定值か ら算出したアマルガム中のナトリウムの活量な Table 2 に記した。

Table 2 に和いて $C$ と $\log r_{298}$ の間には次の如き奏 歌式が成立する。

$$
\log \gamma_{298}=1.336 C
$$

$N(\mathrm{~mol}$ 比) と $C$ との間には $C$ が小なる間次の関係が成 论守名.

$$
\begin{aligned}
N & =(C / 23) \cdot 200.6 /(100-C) \\
& =8.72 C /(100-C) \div 0.0872 C
\end{aligned}
$$

(19) 攺び (20) より 
Table 2 Activities of Sodium in Sodium Amalgam $\left(25^{\circ} \mathrm{C}\right)$

\begin{tabular}{c|c|c|c}
\hline Concentration of amalgam & $\begin{array}{c}\text { Activity coeff. } \\
r_{298}\end{array}$ & $\begin{array}{c}\text { Activity } \\
(a c)_{298}\end{array}$ \\
\hline$C(\%)$ & $N($ mol ratio $)$ & 5.45 & 0.250 \\
0.551 & 0.0459 & 3.36 & 0.112 \\
0.393 & 0.0332 & 2.40 & 0.059 \\
0.289 & 0.0245 & $1.86^{*}$ & 0.033 \\
0.206 & 0.0180 & 1.84 & 0.0316 \\
0.1978 & 0.0172 & 1.43 & 0.0137 \\
0.1102 & 0.0096 & 1.16 & 0.0040 \\
0.0396 & 0.00344 & 1.08 & 0.00183 \\
0.0200 & 0.00174 & 1.00 & 0.0000 \\
0.0000 & 0.00000 & & \\
\hline
\end{tabular}

* Interpolated value

$\log \left(a_{\mathrm{C}}\right)_{298}=\log N \gamma_{298}$

$$
=1.336 C+\log C+\log 0.0872
$$

㕛 Lewis 及び Kraus(7) の測定によれば金属ナトりウム 之 $0.206 \%$ ナトリウムアマルガム閒の起電力は $25^{\circ} \mathrm{C}$ そ佶て $0.8456 \mathrm{~V}$ であるから, Table $2 の 0.206 \%$ マルガム中のナトりウムの活县より

$$
\left(a_{\mathrm{Na}}\right)_{298}=6.474 \cdot 10^{12}
$$

(21), (22) より

$$
\begin{gathered}
R T \ln \left(a_{\mathrm{C}} / a_{\mathrm{Na}}\right)_{298}=T(6.11 C \\
+4.576 \log C-63.475)
\end{gathered}
$$

(17), (18), (23) より

$$
\begin{gathered}
\Delta \bar{F}_{3}=-19,744+T(6.11 C \\
+4.576 \log C+2.780)
\end{gathered}
$$

$\therefore(R T / F) \ln a_{\mathrm{C}} / a_{\mathrm{Na}}=-0.8562$

$$
+(2.650 C+1.984 \log C
$$$$
+1.205) \cdot 10^{-4} T
$$

\section{5. 水銀法食塩電解の理論分解 電圧近似式}

温度 $0^{\circ} \sim 98^{\circ} \mathrm{C}$ の範囲内で，任意の食绵 濃度，任意のアマルガム濃度に捺祆る水銀 法食塩電解の理論分解電圧は (1) 及び (10) 式上り導いた次の（26）式炕より正確江表 される。

$$
\begin{aligned}
& E=4.282-\{14.71+0.0003 T \\
& -1.64 \log T+3.97 \log \left(a_{ \pm \mathrm{NaCl}} /\right. \\
& \left.\left.a_{ \pm \mathrm{NaCl} \text { satu }}\right)-1.98 \log \left(a_{\mathrm{C}} / \mathrm{Na}\right)\right\} \\
& \quad>10^{-4} T
\end{aligned}
$$

但し, $E:$ 理論分解電压 $(\mathrm{V})$

$a_{ \pm \mathrm{NaCl}}:$ 水溶液中の食壏の平均活量

$a_{ \pm \mathrm{NaCl} \text {. satu }}$ 飽和水溶液中の食塩の平均 活量

$a_{\mathrm{C}}$ : アマルガム中のナトリウムの活量

$a_{\mathrm{Na}}$ : 金属ナトリウムの活量

$T:$ 絶対温度 ( ${ }^{\circ} \mathrm{K}$ )

理論分解電圧を求めるため江）式を使
用する際性煩雑な計算は避けられない，しかし理論分 解電庄を構成する諸項を簡易化した (11) 皮び (25) 式 を(1) 式に代入して得た次の近似式はからる計算を極め て谷易ならしめる。

$$
\begin{aligned}
E & =3.371-\left(3.98+3.97 \log a_{ \pm \mathrm{NaCl}}-2.65 C\right. \\
& -1.98 \log C) \cdot 10^{-4} \mathrm{~T}
\end{aligned}
$$

但し，C:アマルガム濃度 $(\%)$

適用範囲

$$
\begin{array}{ll}
\text { 温 度 } & 0 \sim 98^{\circ} \mathrm{C}(\text { ナトリウムの融点 }) \\
\text { アマルガム濃度 } & 0 \sim 0.551 \% \\
\text { 食塩濃度 } & 0 \sim \text { 飽和溶液 }
\end{array}
$$

（27）式を用い，各食壏濃度，アマルガム浱度，温度に拉 ける理論分解電圧を Table 3 と示した. 更飞実用範囲 と招ける(27)式のノモグラフは Fig. 1 の如くである. (27)式及びノモグラをフ用いるには水溶液中の食塩の平 均活量を知ら秝ばなら奴。Fig. 2，Fig. 3 は任意の温 度, 浱度飞淤ける水溶液中の食塩の平均活量を求める便 宜をあたえるこっに使用せる食塭の平均活量は電気化

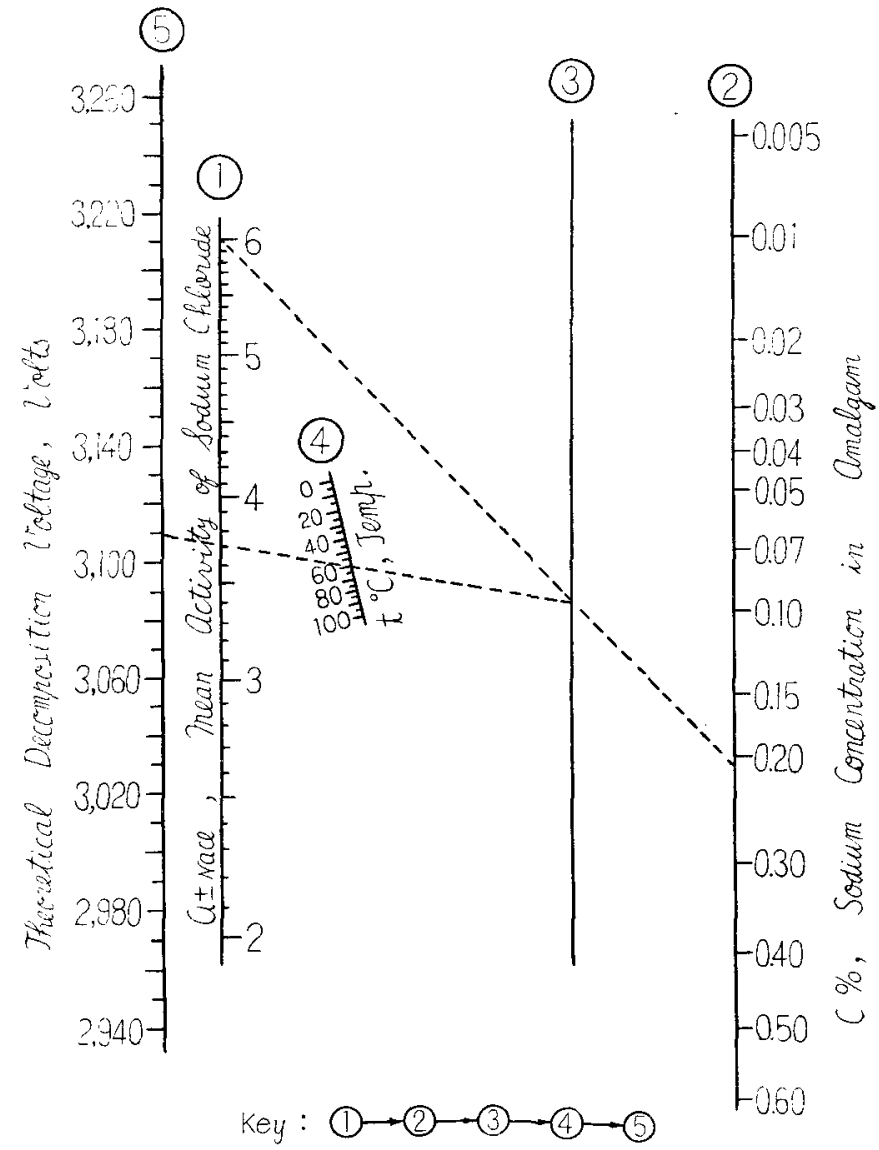

Fig. 1 Nomograph for determining theoretical decomposition voltage of sodium chloride in mercury process 
Table 3 Theoretical Decomposition Voltage of Sodium Chloride Electrolysis with Mercury Cathode

\begin{tabular}{|c|c|c|c|c|c|c|c|c|c|}
\hline & $\mathrm{m} \mathrm{g}_{\mathrm{M} / \mathrm{M} / \mathrm{k} \mathrm{H}} \mathrm{O}$ & 0.1 & 0.5 & 1.0 & 2.0 & 3.0 & 4.0 & 5.0 & 6.0 \\
\hline 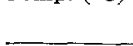 & $\left|\begin{array}{l}\text { Conc. of } \\
\text { Amalgam }\end{array} \mathrm{g} / /\left(15^{\circ} \mathrm{C}\right)\right|$ & 5.8 & 29.0 & 57.4 & 111.6 & 165.5 & 216.6 & 265.0 & $\mathbf{3 1 1 . 0}$ \\
\hline \multirow{5}{*}{0} & 0.551 & 3.408 & 3.340 & 3.309 & 3.277 & 3.256 & 3.239 & 3.224 & 3.210 \\
\hline & 0.289 & 3.374 & 3.306 & 3.275 & 3.243 & 3.222 & 3.204 & 3.189 & 3.176 \\
\hline & 0.206 & 3.360 & 3.292 & 3.261 & 3.229 & 3.208 & 3.191 & 3.176 & 3.162 \\
\hline & 0.1102 & $\mathbf{3 . 3 3 9}$ & 3.270 & 3.240 & 3.208 & 3.186 & 3.169 & 3.154 & 3.141 \\
\hline & 0.020 & 3.292 & 3.223 & 3.193 & 3.161 & 3.140 & 3.122 & 3.107 & 3.094 \\
\hline \multirow{5}{*}{10} & 0.551 & 3.409 & 3.338 & 3.306 & 3.272 & 3.250 & 3.231 & 3.215 & 3.201 \\
\hline & 0.289 & 3.374 & 3.303 & 3.271 & 2.237 & 3.214 & 3.196 & 3.180 & 3.166 \\
\hline & 0.206 & $\mathbf{3 . 3 6 0}$ & 3.288 & 3.256 & 3.222 & 3.200 & 3.181 & 3.166 & 3.151 \\
\hline & 0.1102 & 3.337 & 3.266 & 3.234 & 3.200 & 3.177 & 3.159 & 3.143 & 3.129 \\
\hline & 0.020 & $\mathbf{3 . 2 8 9}$ & 3.217 & 3.186 & 3.152 & 3.129 & 3.111 & 3.095 & 3.081 \\
\hline \multirow{5}{*}{25} & 0.551 & 3.412 & 3.336 & 3.302 & 3.266 & 3.241 & 3.221 & 3.205 & 3.189 \\
\hline & 0.289 & 3.375 & 3.299 & 3.265 & 3.228 & 3.204 & 3.184 & 3.167 & 3.152 \\
\hline & 0.206 & 3.359 & 3.284 & 3.250 & 3.213 & 3.189 & 3.169 & 3.152 & 3.137 \\
\hline & 0.1102 & 3.336 & 3.260 & 3.226 & 3.190 & 3.165 & 3.145 & 3.129 & 3.113 \\
\hline & 0.020 & 3.285 & 3.209 & 3.175 & 3.139 & 3.114 & 3.094 & 3.078 & 3.063 \\
\hline \multirow{5}{*}{40} & 0.551 & 3.414 & 3.334 & 3.299 & 3.260 & 3.234 & 3.213 & 3.195 & 3.179 \\
\hline & 0.289 & 3.375 & 3.295 & 3.260 & 3.220 & 3.195 & 3.174 & 3.156 & 3.140 \\
\hline & 0.206 & $\mathbf{3 . 3 5 9}$ & 3.279 & 3.244 & 3.204 & 3.179 & 3.158 & 3.140 & 3.124 \\
\hline & 0.1102 & 3.334 & 3.255 & 3.219 & 3.180 & 3.154 & 3,133 & 3.116 & 3.099 \\
\hline & 0.020 & 3.281 & 3.201 & 3.165 & 3.126 & 3.101 & 3.080 & 3.062 & 3.046 \\
\hline \multirow{5}{*}{60} & 0.551 & 2.418 & 3.333 & 3.294 & 3.253 & 3.225 & 3.203 & 3.185 & 3.167 \\
\hline & 0.289 & 3.376 & 3.291 & 3.253 & 3.211 & 3.184 & 3.162 & 3.143 & 3.126 \\
\hline & 0.206 & 3.359 & 3.274 & 3.236 & 3.194 & 3.167 & 3.145 & 3.126 & 3.109 \\
\hline & 0.1102 & 3.333 & 3.248 & 3.209 & 3.168 & 3.140 & 3.118 & 3.100 & 3.082 \\
\hline & 0.020 & 3.276 & 3.191 & 3.153 & 3.111 & 3.083 & 3.061 & 3.043 & 3.025 \\
\hline \multirow{5}{*}{98} & 0.551 & 3.424 & 3.331 & 3.289 & 3.243 & 3.212 & 3.188 & 3.168 & 3.149 \\
\hline & 0.289 & $\mathbf{3 . 3 7 8}$ & 3.285 & 3.243 & 3.196 & 3.166 & 3.142 & 3.122 & 3.103 \\
\hline & 0.206 & 3.359 & 3.266 & 3.224 & 3.177 & 3.147 & 3.123 & 3.102 & 3.084 \\
\hline & 0.1101 & 3.330 & 3.236 & 3.194 & 3.148 & 3.118 & 3.094 & 3.073 & 3.055 \\
\hline & 0.020 & 3.266 & 3.173 & 3.131 & 3.085 & 3.054 & 3.030 & 3.010 & 2.991 \\
\hline
\end{tabular}

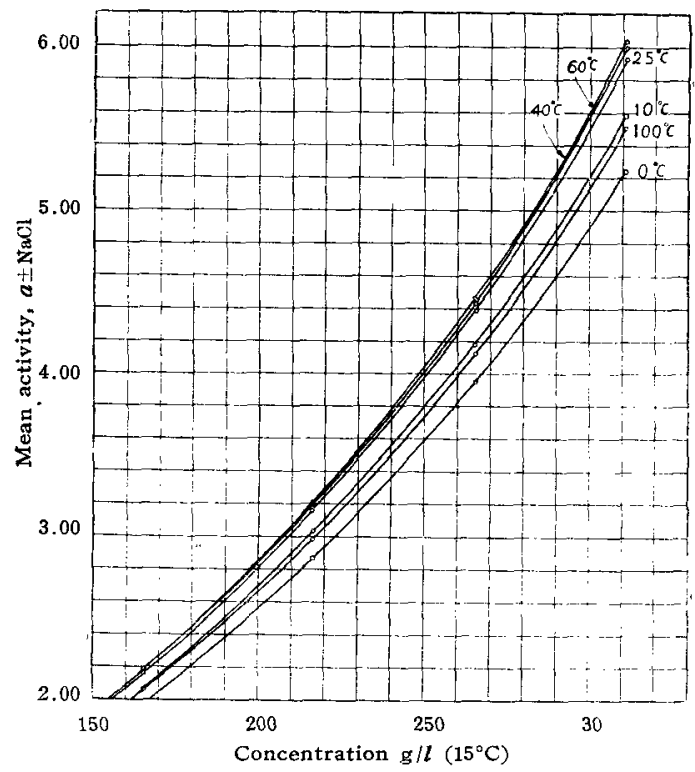

Fig. 2 Mean activity-concentration curves of sodium chloride in the electrolyte
学便譼 ${ }^{(5)}$ 及び Conway ${ }^{(6)}$ の Electrochemical data に 記載された平均活量係数並びここれ等の外挿值より計算 した.

理論分解電圧近似式を導くに際して伴った誤差心次の 如くてある。

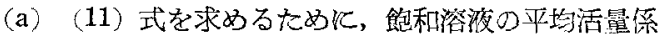
数壮 $25^{\circ} \mathrm{C}$ の值以外はすべて外插により決定した. 久こ の近似式は䛈導の過程で $+0.002 \sim-0.001 \mathrm{~V}$ 以内の愦 差を生じうる。

(b) (25) 式誘導㒄し，ナトリウムがアマルガムに 溶解するときの微分熱含量は温度に拘わらず一定上見敒 した. 又（25）式より得た近似值夻活量の計算值上比䩪 すると $-0.0009 \sim-0.001 \mathrm{~V}$ 以内の誤差㕝生ずる.

飽和溶腹の平均活量係数を外挿により求めた場合, 理 䛧分解電压に及ぼす誤差山㮖かと見做してょい，徒って ナトリウムがアマルガムに溶解する際の街分熱合量が道 用温变の範囲内で一定と見做す限り（27）式琿用に際し 能り得る愦差は $\pm 0.003 \mathrm{~V}$ 以内である.

水銀法食塩電解理論分解電辰を(27)式より求めるとき

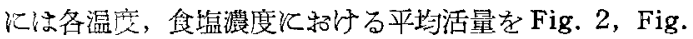




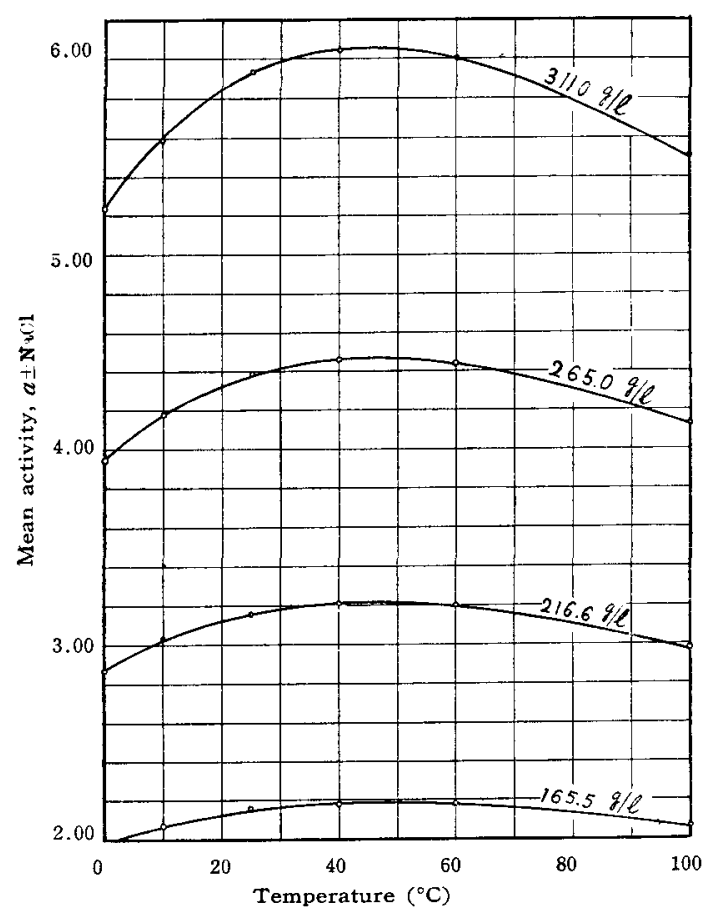

Concentrations of sodium chloride in the electrolyte ars expressed as $\mathrm{g} / \mathrm{l}$ at $15^{\circ} \mathrm{C}$

Fig. 3 Mean activity temperature curves of sodium chloride in the electrolyte

3 亿よるか又その都度計算して求めねばならぬ.この手 続を避けるため食㙁の平均活量を一定温度，例光ば $25^{\circ} \mathrm{C}$ の値で代用すれぼ，ノモグラフ作製の場合平均活量の日
盛は食塩濃度の目盛で表すことが出来るので一層簡殚に なる.しかしか〉る近似定行うときは上記適用範囲で

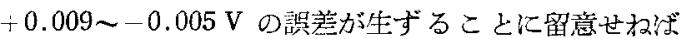
\%5\&.

\section{6. 総 括}

(a) 熱力学的計算により水监法食塩電解の理論分解 電圧を表す䜣似式を求めた。この近似式の適用範囲温

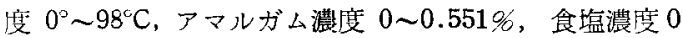
〜飽和溶滩の間で成立し，近似計算飞伴弓誤差は，士 $0.003 \mathrm{~V}$ 以内上見做される.

(b) 近似式を食塩濃度 (平均活量)，アマルガム浀度 及び温度の実用範囲を採ってノモグラフに作製した。

終りに臨み本研究を行うに当り終始御兴切なる御指導 を賜った京都大学教授岡田辰三博士並びに同学助教授吉 呮四郎博士に衰心より感謝る捧げる。

（昭 $32 \cdots 5-31$ 受理）

\section{文 献}

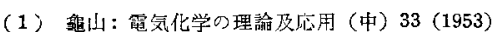

(2) 電気化学便篭, 81, 83 (1953)

(3) 闹上 88

(4) International Critical Table, 7, 303 (1930); Lewis, Randall : Thermodynamics (1923)

(5) 電気化学便覧 128 (1953): Harned, Owen : The Phys. Chom. of Electrolytic Solutions (1943)

(6) Conway: Electrochemical Data, 76 (1952)

(7) Lewis, Kraus: J. Am. Chem. Soc., 32, 1459 (1910)

(8) Richard, Conant: ibid., 44, 601 (1922)

(9) 柴田 (Shibata), 織田 (Oda) : 日化 (J. Chem. Soc. Japan Pure Chem. Sec.), 52, 352 (1931)

(10)柴田 (Shibata), 織田 (Oda)：同誌 ibid., 52, 365 (1931)

(11) 吉沢 (Yoshizawa), 武蕂 (Muto) : 工化 (J. Chem. Soc. Japan, Ind. Chem. Sec.), 56, 387 (1953)

\title{
陰陽複合イオン交換膜の性質についで
}

\section{On the Properties of Double Membrane for Ion Exchange}

\author{
織田健一, 村越搨渗, 斎藤武男** \\ Kenichi ODA, Masahiko MURAKoshi and Takeo SAIto
}

\section{1. 緒 言}

陽イオン交換膜及び陰イオン交換膜の有する興味ある 電気化学的性質は，すで多くの研究者によって注目せ られ，その基礎的及び応用的研究は数多く発表されてい る.これ等の膜沟一，不均一の別々あるが何れる膜全 体が陽イオン交換性或いは陰イオン交換性をもったもの である、しかるに著者等は一枚の膜ではあるがその一雨

*1オン交換膜の研究（第 3 埌） Studies on Ion Exchange Membranes (Part 3)

** 財団法人野口时究所（東京都板鹪区板橋町 6 つ3569）

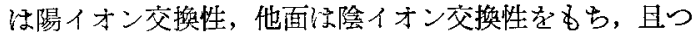
膜面の方向のみならず膜に直角な方向にも良好な電導性 をもつ膜（以下のような膜を陰陽複合イオン交換膜，略 して複合成莫と呼ぶを製造することが可能であり,これが 極めて與味ある性質を示すことを芫出したので，艺の製 浩这びに性質に関する研究を行ってきた。海外に於てる Frilette ${ }^{(1)}$ がこの問題に着目し，複合膜（彼ね Bipolar Membrane と称した）に電流を与学ることにより $\mathrm{H}^{+}$及 び $\mathrm{OH}^{-}$が発生すること軓述べているが，その膜の性能 は末だ良好でなく，行った测定も極めて大きな䛊差が予 想されるような方法であって複合膜の作用を検討する方 